\title{
Can an Evolutionary Perspective Shed Light on Maternal Abuse of Children?
}

\begin{abstract}
Although the theory of evolution lies at the heart of contemporary biology, its influence on the study of child psychology and psychiatry has been limited. In earlier work we have argued that evolutionary thinking has much of value for clinicians in these fields. Here, we explore the possible significance of evolutionary theory for understanding child abuse by mothers, particularly neglect, emotional abuse and physical abuse. We draw on the research of anthropologists, primatologists and evolutionary theorists to make predictions about the environmental circumstances under which one would expect such abuse to be more prevalent. We discuss how in modern, Western cultures there is less understanding of the circumstances that may influence, even predispose, a mother to limit her emotional and material commitment to an infant or child. We use four short vignettes of clinical cases and one longer case to illustrate the insights offered to clinicians by an evolutionary approach. We see our work both as contributing to greater understanding of these matters and as facilitating more compassionate approaches when working with women in such circumstances.
\end{abstract}

\section{Key words}

child, child abuse, evolution, mother, neglect, parenting

\section{Introduction}

Child abuse is a common and serious problem. The majority of published contributions to understanding the issues focus on describing what happens and how that influences the child, now and in the future, in terms of intergenerational transmission (WHO, 2020). Only a few thinkers in child psychiatry or psychology have focussed on how evolutionary science may provide an additional, wider perspective (e.g., van IJzendoorn et al., 2020). In this article, we focus on how evolutionary theory may help us understand why some mothers abuse their children physically, emotionally or through neglect. Our hope is that a deeper understanding of the underlying reasons for child abuse will help inform therapy, both for mothers and their children.

Tinbergen described the four aspects that need to be considered in order to understand a behaviour from a range of perspectives (Tinbergen, 1963): causation (mechanism), survival value (function), ontogeny (development) and evolution. Most of the thinking about child abuse currently focuses on development and mechanisms. A considerable amount is now understood about how exposure to trauma affects the set points of the stress systems and 
can lead to long-term physical and emotional ill-health (Heim et al., 2019). We also know that mothers who are stressed and have little or no support are at higher risk of abusing their children (St-Laurent et al., 2019) However, there is little thinking in child psychology and psychiatry as to the underlying reasons as to why this might happen - what Tinbergen meant by the 'survival value' of a behaviour.

As a group of therapists and scholars interested in how evolutionary science might inform clinical work, we have been meeting regularly at the Tavistock Clinic for a number of years to look at ways that contemporary ideas about evolution can inform both theory and practice in the world of mental health. We have published articles looking at child development and behaviour (Swanepoel et al., 2016), ADHD (Swanepoel et al., 2017) and gender diversity and sexuality (Wren et al., 2019), proposing ways that evolutionary thinking might enhance other ways of understanding these areas and - most importantly contribute to reducing stigma by making sense of feelings and behaviours that might otherwise seem merely aberrant. We believe this approach also has something of value to offer the understanding of child abuse and neglect.

We tread delicately here. It is not our contention that pursuing an evolutionary understanding of such behaviour means that we deem it to be acceptable; nor do we advocate doing nothing to help change the situation. Rather, what we are proposing is that the issue of abuse and neglect be considered not just through a safeguarding lens (if focusing on the child(ren)) or legal lens (if focusing on the mother), but also by trying to make sense of these behaviours.

For purposes of simplicity and clarity, our main focus is not on abuse by fathers or other adults, harm carried out by extended family and step-parents (who might have quite different motives and causes in evolutionary terms (Daly \& Wilson, 1996)) nor sexual abuse, which might similarly have different causes (Mathews, 2019). Within our chosen scope, we hope that one consequence of this article will be greater compassion towards all mothers who abuse their children, as well as promoting a wider understanding of how human endowments make us all, for better or worse, who we are.

\section{Addressing reservations to an evolutionary approach}

There are probably few child psychologists and psychiatrists who do not accept the theory of evolution. Most will be familiar with its key tenets as set out by Charles Darwin (and others) over 150 years ago: that random variations in what we now know as genes interact with the environment to shape the development of individuals; and those individuals who are better suited to that environment are relatively more successful in producing surviving offspring. (It is worth pointing out that the notion of 'survival of the fittest', a term first 
coined by Herbert Spencer in 1864 , is commonly misunderstood: evolutionary science describes how those individuals that have the best 'goodness of fit' with their environments are the ones whose genes survive, even though they may not the strongest or the fastest or the smartest. If evolution was all about strength, speed or intelligence we wouldn't nowadays have dormice, tortoises or barnacles.) In spite of this acceptance, many mental health professionals harbour reservations about applying evolutionary perspectives to mental wellbeing, as well as to behaviours such as maternal abuse that bring about suffering and harm. Two reservations are commonly mentioned.

First, some are concerned that evolutionary approaches promote genetic determinism (the idea that genes determine everything including sexuality or specific mental illnesses, regardless of the environment) (Lynch et al., 2018). They may not be aware that virtually no evolutionary thinkers now hold such views, nor that modern evolutionary research takes a far subtler approach, looking instead at the complex interactions that occur between genes and environmental influences (Kampourakis, 2017). Indeed, the entire field of epigenetics addresses an aspect of this interaction and is widely embraced within the field of evolutionary studies (Scott-Phillips et al., 2011). A related fear is that evolutionary explanations may claim to override alternative approaches to understanding causation, from biochemical to psychodynamic or social ones. In reality, evolutionary thinkers, just like psychologists and psychiatrists, are entirely comfortable in moving between different levels of explanation, which often turn out to be not only compatible but complementary.

Second, some people are puzzled about how behaviour that has such deleterious effects can be considered to be 'adaptive' in an evolutionary sense. The answer to this is that adaptation always depends on trade-offs, and some circumstances the 'least worst' trade off may be the best available. In the most adverse environments it is preferable from the point of view of survival and reproduction to experience suffering rather than to die. Even in humans, such behaviour is not necessarily the consequence of conscious decision-making. Selective pressures direct how people are more likely to behave, so that those in the most fortunate circumstances may have the luxury of being less vigilant towards perceived danger, for example, while others in more challenging circumstances will automatically know that a low level of vigilance would carry high risks for them.

In raising the possibility that child abuse can be adaptive, we do not, of course, mean adaptive for the abused child, but for the mother. We should also stress that our contention is not that all instances of abuse are adaptive - abuse can be pathological. Rather, we will argue that there are specific circumstances under which we might expect maternal abuse of children to occur for reasons that, from an evolutionary perspective, may be adaptive for the mother and other children. Our point is that in our evolutionary past, environments were often uncertain, unstable and stress-inducing, such that at times maternal responses of ambivalence or abandonment towards their infants might have aided the likelihood of on maternal abuse of children? Clinical Child Psychology and Psychiatry. DOI: 10.1177/1359104520974418. 
survival for the mother as well as for other, stronger children (whether born or yet to be born). The contemporary contexts in which mothers and their children live involve dramatic change from these earlier sets of circumstances and, in our view, it is likely that current environmental demands may often not fit well with what evolution has prepared mothers to cope with. For example, a woman today may be the sole carer for her children, with little community support available, perhaps employed outside the home on a wage that cannot adequately support a family, and requiring her to call on professional childcare. Such a mother may experience particular kinds of stress - not least the pressure resulting from the prevailing idealisation of the mothering role - and she may, as a consequence, behave towards her children in withdrawn, rejecting or punitive ways. Such behaviour, that would invariably have substantial negative impact on the children, is hard to think of as 'adaptive' in an evolutionary sense. And yet, as we have argued previously, in our paper on ADHD (Swanepoel et al., 2017), adaptation always depends on trade-offs, and in some circumstances the 'least worst' trade-off may be the best available. Clinicians and policy makers - taking the mother, the child and the environment into account - need to consider what might be desirable and feasible, both in society and for specific families, to lessen the mismatch.

A particular obstacle for mental health professionals to considering an evolutionary view of abuse is that many associate maternal attachment with the idea that mothers and infants have evolved a need to remain closely bonded in order to protect offspring during the vulnerable early stages of life (Bowlby, 1969/1997). The modern evolutionary approach is considerably more nuanced than this. Perhaps the most influential research in this respect has been that of the primatologist Sarah Blaffer Hrdy $(1999,2009)$, who has argued, on empirical grounds, that maternal responses to their infants may lie, for adaptive reasons, anywhere on a spectrum from close bonding to ambivalence or abandonment, largely according to circumstances, including the degree of safety or danger. Hrdy began by studying Hanuman langurs for her PhD (Hrdy, 1977) and went on to use what she had learnt about maternal behaviour, including infanticide, in that species to illuminate our understanding of maternal infanticide in other primate species, including tamarins, marmosets and humans. Although the notion that maternal infanticide might sometimes be adaptive in humans may seem counterintuitive in a modern Western society where child mortality is extremely low, it is perhaps easier to appreciate the function of such a range of possible behavioural responses to infant(s) in traditional subsistence societies where between $30 \%$ and $60 \%$ of children typically die before adulthood (Gurven \& Kaplan, 2007). In such societies, a mother may have to calibrate (whether consciously or otherwise) her response to her infant in relation to available resources, the needs of any older children, and the strengths and vulnerabilities of the new infant. 


\section{Anthropological research and clinical implications}

In considering the different factors that determine maternal responses to their infants across different environments, the anthropologist Daniela Sieff (2019) categorises these in terms of maternal factors and those relating to the children themselves. In the following section, we broadly follow her schema and draw on evidence including studies she cites.

\section{Maternal influences}

Some of the most in-depth anthropological research into hunter-gatherer people has focussed on the!Kung of the Kalahari Desert. Until quite recently, the traditional role of women was to spend much of the day gathering berries and tubers, while carrying and breast-feeding their children until around the age of four-and-a-half. Doing this with more than one child at a time was a task that would put the survival of both mother and children at risk. As late as the 1960s, levels of infanticide were recorded at one per cent (Howell, 1979). Infanticide was sanctioned by a belief system that did not consider life to begin at birth but later, once the child was accepted into the community. Infanticide in humans is not restricted to the !Kung. Far from it. While the issue of the extent and reasons for infanticide in humans has been controversial, it has been observed in both traditional and modern societies around the globe and in both historical and contemporary times, as has selective allocation of resources to stronger siblings at the expense of weaker ones (Milner, 2000; Hrdy, 2009; Hanlon, 2016).

As an example, Scheper-Hughes (1992) studied Brazilian shanty towns with high infant mortality, disease and dire economic conditions, and observed mothers distancing themselves from babies who were unlikely to survive. Mothers described some babies as 'strong' and others as lacking the will to live. The latter were often allowed to die in a way that might seem cruel to Western eyes. Timing is often crucial; a mother might abandon a child when circumstances are not propitious for childrearing, yet lovingly and devotedly care for another child born in more hopeful times. Younger mothers in poor circumstances are more likely to abandon offspring, perhaps hoping that they will have other chances, and we know that neonaticide is more commonly committed by young, poor mothers who have received little support (Friedman et al., 2005).

An analogy in modern Western societies might be the favouring of one child over another, either in terms of either material or social investment (see Case example 1). Typically, but not necessarily, we would expect that the younger of a pair of siblings is more likely to be the weaker of the two, meaning that, from an evolutionary perspective, we would predict that younger siblings are more likely to be the focus of maternal abuse unless there are other factors involved, e.g., the older sibling is less healthy or the present sexual partner of 
the mother is the parent of the younger sibling but not the older. (All cases are fictional but based on real clinical instances.)

\section{Case example 1}

Jane, a 16-year old girl, presented to mental health services following an overdose. She said that her mother had a new partner and was pregnant with a baby girl. Jane said that she was being "replaced". Unfortunately, there appeared to be some truth in that perception, as her mother did not want Jane to live with them and the new, very much younger half-sister. Jane ended up being admitted to a psychiatric inpatient unit due to ongoing suicide attempts. Her mother, who was not in paid employment, supported Jane being discharged to supported accommodation, as she said it was important to keep her partner happy, who had a good job, and to care for their baby. Her mother said that Jane was now old enough to fend for herself, in spite of Jane's clear distress.

A key contribution of Hrdy to the area of child-rearing has been her understanding of this as primarily a social and communal activity as opposed to the individualist (or dyadic) way this is generally understood in contemporary Western societies (Hrdy, 2009). She suggests that humans are a cooperative breeding species, unlike many primates, and rear children in groups. In a traditional society a woman with limited social support would be unlikely to be able to help all her children survive, whereas one surrounded by female relatives, especially grandmothers and teenage daughters would be more likely to. There is a parallel to this in the way that Western women who are well supported by others are more likely to develop secure attachments with their infants than those who are unsupported (Myers \& Johns 2017). Grandmothers can also help grandchildren directly by standing in for mothers when they are incapacitated (see Case example 2).

\section{Case example 2}

A child psychiatrist was struck by the differences between two children from unrelated single-parent families who were seen around the same time. Harry and Paul were both 12 years old and had mothers who were severely depressed. Harry's mother had no family support and Harry felt that it was his responsibility to care for his mother. Harry dropped out of school to stay at home to look after his mother. He was depressed and anxious - and needed professional help. In contrast, Paul's grandmother had moved in to help while Paul's mother was unable to manage due to her severe depression. Paul was able to continue to go to school, because he knew his grandmother was around to care for his mother. Paul's symptoms were mild. 


\section{Children's characteristics}

Studies of several hunter-gather peoples have shown that a child's survival depends initially on an examination of the newborn, with mothers considered to have the responsibility to dispose of a baby who seems unlikely to survive the demands of a nomadic life. Here too there is a correspondence to industrialised societies where mothers of twins have been noted to give more attention to a healthier twin without necessarily being aware of doing so (Minde et al., 1990) (see Case example 3). In the same way, children with disabilities or neurodevelopmental disorders are much more likely to become subject to abuse and neglect (NICE, 2017). Hence, the effects of the disabilities and disorders may be compounded by the parents' behaviour in response.

\section{Case example 3}

Nicole presented to services at the age of 12 , due to anorexia. She was a younger twin, who had experienced some physical and cognitive difficulties from birth, in contrast to her non-identical sister Nina, who was healthy, developed normally and excelled both at school and in music. Nicole felt that Nina was the favoured child, as their mother was a music teacher who rated academic excellence and musical talent very highly. Nicole became convinced that she had to find something that she was good at and in which she could outcompete her sister. She started running and noticed that she could run faster than her sister when she exercised more and weighed less. Nicole felt driven to exercise excessively, while restricting her intake of calories, as she explained that she was convinced that if she did not "perform" as well as her sister, she would be "worthless". Her weight dropped, her health deteriorated and she needed meal support at home. Her mother tried to engage an au pair to look after Nicole, so that she would be free to support Nina with homework and piano lessons. Professionals were struck by the mother's clear preference for Nina and unwillingness to spend time and effort with Nicole. It was only when professionals pointed this discrepancy out to the mother that she became aware of her unconscious bias and agreed to engage an au pair to help Nina while she supported Nicole herself. This strategy was successful and Nicole stopped being so fixated on having to win races in order to get her mother's attention.

Another factor influencing maternal care is the child's own disposition. In a study of foster children, for example, more active infants received greater attention (Bowlby 1969/1997, p.341). From an evolutionary perspective this makes sense - by and large, an active child is likely to be healthier than one who is lethargic. Additionally, there may be differential responses by mothers according to the infant's sex (Sieff et al., 1990). In India, for example, sick new-born girls are only half as likely to receive medical treatment as sick new-born boys 
and these sex-biased effects continue to disadvantage girls (Singhi et al., 2013). In general, female infanticide is commoner in societies where there is a higher chance that women might remain unmarried and childless (Dickemann, 1979); conversely, where older children commonly help to bring up younger ones, there is more favourable behaviour towards girls (Bereczkei \& Dunbar, 2002; Turke, 1988). An additional factor can be where one child's disposition helps them to relate to a parent more effectively than a sibling is able to (see Case example 4).

\section{Case example 4}

John was diagnosed with autism when he was a toddler. He presented to mental health services with depression and anxiety at age 12 . He said that his mother was very critical and strict with him. The family therapist believed that it was very likely that the mother was autistic too and did not have the skills to manage emotional communication and resolve conflicts. Interestingly, John's younger brother James had no problems with their mother at all. James was not autistic and was able to recognise her emotions and stay out of her way when she was irritated. James was also able to appease their mother. Sadly, the mother used the fact that there were no problems with James as evidence that all the problems lay with John.

Citing evidence from anthropological and evolutionary studies does not mean supporting the idea that any particular kind of behaviour is either inevitable or necessarily justifiable. Quite the contrary, it is a way of indicating how far human behaviour is determined by the environment, but retains an innate potential to become channelled in different directions. From a clinical point of view, this evolutionary understanding has two advantages. The first is that it can enhance the understanding of clinicians, along with their patients and clients, regarding the determinants of behaviour that might otherwise seem inexplicable or pathological. The second advantage is that it may point us towards policies and practices that are may lessen the likelihood of such behaviour.

In terms of helping mothers, an evolutionary perspective can help us to let go of an idealised view that a strongly positive maternal bond in all circumstances is 'natural', and that those who feel negatively towards their children are in some way deviating from what is 'normal'. It is, of course, a core presumption of all psychodynamic approaches to understanding human behaviour that there are times when any of us can feel murderous rage. Helping mothers to see their feelings and behaviours in a wider human context may be particularly helpful in alleviating an overpowering sense of guilt or shame that may attend unexpected negative feelings that in other societies might be seen as entirely comprehensible. In the same way, evolutionary awareness may be of help to patients and clients who feel unloved or unlovable on account of maternal negativity during their infancy and childhood (Schore \& Sieff, 2015).

Wren, B., Launer, J., Music, G., Reiss, M. J. \& Swanepoel, A. (2020) Can an evolutionary perspective shed light on maternal abuse of children? Clinical Child Psychology and Psychiatry. DOI: 10.1177/1359104520974418. 
In the words of Daniela Sieff:

Challenging the sentimental idealism that surrounds "mother" can help women to understand their ambivalence in a more human context. Maybe this mother already has a young child whom she is struggling to look after; maybe her child is weak or disabled; maybe an economic downturn means that resources are scarce; maybe she is without support. Although in today's world, in many countries, her children will survive, they would not have done so throughout most of our evolutionary history, and the mother's ambivalence may, in part, reflect this deeper history. Once a woman begins to understand this broader reality, she can start to deconstruct and integrate the shameful feelings of indifference or hostility that she sometimes feels for her infant, while fostering the kind of self-compassion that sets the stage for genuine change in both her internal and external worlds. (Sieff, 2019, p.29)

\section{A life-history take on child abuse, trauma and neglect}

One further evolutionary perspective is relevant to this article. There are a series of nonconscious 'choices' that an individual (in any species) has to make: when to start reproducing, how far apart to space offspring, how many offspring to nurture, and so on, that are also part of navigating life. Will an individual leave more surviving offspring if it waits before starting to reproduce till it has grown to a larger size, and has a more extensive social network before it starts reproducing? Or if it waits, does it have too great a risk of being eaten by a predator before it has a chance to have any progeny? The body of research that addresses these kinds of questions is called life-history theory (Reiss, 1990; Stearns, 1992).

Humans, like all animals, constantly adapt to their environments. Such very early adaptations trigger neurobiological patterns that have a profound effect throughout the lifespan, at the levels of the psychological and biological systems. Those born into highly stressed worlds, especially when there is a high level of unpredictability (Simpson, 2019), tend later in life to have a speeded-up metabolism, faster heart rate and more activated stress response system and develop what some call a fast as opposed to a slow life course strategy, being more susceptible to physical and mental disease and early death. Contrary to what some might presume, this is a survival strategy and it is seen in a range of mammals, not just humans. Any too trusting and complacent individual might well have met a violent end before they could reproduce (strictly speaking, reproduce as much as would otherwise have been the case). In some situations, wariness, vigilance and lack of trust enhances immediate survival, but at psychological and health costs. 
Girls raised in dangerous, stressed or abusive environments are more likely to have a range of mental health issues, are typically more avoidant or reactive, and are less able subsequently to parent as successfully as might otherwise have been the case any children that they go on to have. In the West, girls with insecure attachments often reach puberty earlier (Ellis \& Del Giudice, 2019), as do those born into highly stressed families, or adopted from poor quality orphanages, and are more likely to be sexually active younger, and reproduce earlier and more often. A speculative evolutionary explanation for early reproduction is that in a dangerous and unpredictable world those who leave it too long before they reproduce might well die before they have the chance to do so. Similarly, a speculative explanation for why women in such situations have more children is because sadly it is likely that each child has a lower chance of surviving to reproduce itself than it would have had, had it been born in a better environment. All this links to why animals, including humans, tend to take more risks when their environments are unstable and stressinducing, becoming more involved in violence or sexually promiscuous behaviour, for example. Children with secure attachment styles, living in safe, relaxed and relative stable and therefore predictable environments, non-

consciously pick up very different messages, such as that it is sensible to wait later to reproduce, it is fine to have fewer children but to invest more in each one, and that one can rely on long-term, stable relationships (Music, 2016).

When given cues that suggest a dangerous or uncertain situation, those brought up in poorer socio-economic circumstances tend to take more risks, while those brought up economically advantaged tend to take the slower, more risk-averse strategy (Griskevicius et al., 2011). A faster life course is thus an adaptive response, enhancing the chances of surviving in threatening environments, but comes with very substantial costs. Childhood abuse has profound long-term effects on both physical and mental health, including future parenting capacities, the number of children conceived and the investment in each.

It is in early childhood that the seeds of huge differences in health outcomes and emotional wellbeing are sown. Studies of Adverse Childhood Experiences (ACEs) provide perhaps the most marked evidence of the costs of damaging childhoods (Danese \& McEwen, 2012). Thus, from an evolutionary perspective we see a trade-off. Immediate survival trumps people's longterm physiological and mental health, undermining empathic parenting. The good news is that these cycles, when recognised, can be broken (see Case example 5). For example, the stress systems of adolescents adopted from orphanages into caring homes can be recalibrated in puberty (Gunnar et al., 2019) and while early stress predisposes girls (at least in the West) to early menarche, this effect is buffered by secure early attachment relationships (Sung et al., 2016). Early menarche linked to adversity and stress is seen as a transdiagnostic indicator of 
likely mental health problems, which can interfere with the ability to parent (Colich et al., 2020).

The evidence is clear that the more adverse the early experiences a child has, the greater the likelihood of a faster life course, which entails a greater likelihood of physical and mental illness, less stable relationships and work lives and, on average, dying younger (Dube et al., 2003).

\section{Case example 5}

Marsha was 18. She had just given birth to her third child, Jo, her first son. The first two had been taken into care within six months of their births, on the grounds of neglect. Marsha had an edgy feel, a tough exterior belying a fragile emotional state hidden beneath reactive emotional dysregulation. She had been in and out of care herself, her mother a drug-using sex worker and her father violent and probably a pimp. In an assessment centre Marsha was self-conscious and trying hard to impress but struggled to spend time with Jo, and when she did her seemingly loving gestures had, on close inspection, a tough harshness about them. When feeding she held Jo too tightly, and thrust him away afterwards. When he cried, Marsha seemed to flinch and then flashed bared teeth and looked as if she might hit him, before trying to soothe him in a way she seemed to think that others expected of her. Her ability to think about Jo was limited, showing little capacity for mind-mindedness and manifesting low empathy and little love. She was controlling, trying to force her expectations and pace on her son, unable to pick up his discomfort or tension. Jo seemed to have given up, not expecting softness, or loving responses and his eyes already had a glazed look. While it was the bruises and soiled nappies that evoked social services action, it was the emotional mis-attunement that was most painful and worrying.

Witnessing violence has a profound effect on a child's brain and nervous system. Marsha's stress system would have been affected even prenatally due to the violence and fear in her environment, leading stress hormones to cross the placenta and resulting in her being born with a highly activated HPA (hypothalamic pituitary adrenal) axis. Marsha's early life was lived in an atmosphere of fear, indeed terror, oscillating with profound neglect when she was left alone for hours, patterns she was repeating with Jo.

It is easy to condemn mothers such as Marsha, or be punitive of them, but Marsha was in fact the victim of her own history and that of previous generations. She had been exposed to violence and inappropriate sexuality from early in her life and she too became, as is common, a classic victim turned perpetrator. But there is another 
way of looking at Marsha's development: in evolutionary terms she had developed an effective way to survive in her early environment.

She would have developed a personality rooted in expectation of danger, giving rise to a constant state of high alert, a hyper-aroused sympathetic nervous system, a reactive 'fight' system. This is an adaptive response to ongoing fear and danger but the body pays the price in heightened cortisol, lowered immune systems and an inability to calm down. Marsha exhibited massive wariness and distrust, and had had little familiarity with giving or receiving love and understanding. Such negative experiences give rise to a speeded-up metabolism, and a turning-off of brain pathways involved in empathy, emotional regulation and executive functions. These are helpful evolved mechanisms for dealing with danger. When there is threat to our lives, we need to go into major survival mode as all mammals do. However, most species, and indeed secure children and adults, quickly calm down when danger passes, heart-rates returning to normal for example. People like Marsha experience life as one lived-in, constant life threat, and do not trust in or recognise the presence of benign figures. For understandable reasons they do not trust softness, kindness or vulnerability, and often glorify strength, power and aggression. This makes sense of how Marsha struggled to be with Jo in a kindly way; the harsh and frankly abusive set of exchanges, which looked like callousness, can be seen as explicable adaptations to a terrifying early life.

For reasons of survival it would make little evolutionary sense to for Marsha to be open, trusting and loving. Indeed, she would often resort to even more worrying and ancient evolved defence mechanisms in the face of violence and threat, going into an almost shut-down glazed state, that primitive survival response of numbing, dissociating, a 'flop' or dorsal vagal response shared with other species (De Thierry, 2020). Marsha's shut-down glazed states were a sign of serious life-threatening trauma for which she needed help, but it also led her seeming to be not present and led to serious neglect of Jo. Again such 'flops' or numbed states are an effective, long-evolved defence. Reptiles, the evolutionary precursors of mammals, can survive without breathing for many minutes and such stillness and looking dead puts off potential predators. In humans, though, such responses are a sign of serious trauma and often linked with intergenerational abuse.

Thus, Marsha was both a perpetrator and also a victim who had had too little good experience to have much chance of growing into an adult capable of feeling and giving love and care, of experiencing ease, hope and emotional wellbeing. She had done what our evolutionary history has primed us to do, to learn early that survival requires heightened sympathetic nervous system activation or, in extreme situations, a numbed shut down. This is how our evolutionary heritage programs our 
minds, bodies, brains and nervous systems very early for the world we learn to expect, and such early learning is hard to shift, unless we get the right help.

Marsha and Jo were referred to an intensive parenting program and Marsha learnt to be curious about Jo and to think about how he might be feeling. Staff treated Marsha with kindness and understanding and helped her do the same with Jo. Marsha was able to become more attuned and reflective, which had a positive impact on her relationship with Jo.

\section{Conclusion}

The challenge of applying evolutionary thinking to maternal abuse of their children lies in addressing the cultural presumption that women evolved to love their infants automatically, selflessly and whatever the circumstances. Indeed, mental health professionals, lay people and mothers themselves often tend to assume that the 'ideal mother' is synonymous with the 'natural mother'. Research in evolution and anthropology tells us that this belief is not sustainable. When we consider insights developed from the field of evolutionary biology and data gathered from anthropological fieldwork, we see that maternal love did not evolve to be unconditional and inevitable. Rather, women's maternal emotions (and the behaviours that are influenced by those emotions) have evolved to be sensitive to a host of contextual factors. A better informed and more nuanced understanding of maternal behaviours and their determinants may enable clinicians, patients and clients alike to take a less idealistic but more realistic and more compassionate view of how mothers behave towards their children, potentially to the benefit of mothers, their children and society more generally.

\section{Acknowledgements}

We are very grateful to Daniela Sieff for invaluable discussions and detailed feedback on earlier versions of this manuscript and to three reviewers for helping us improve the submission.

\section{References}


Bereczkei, T., \& Dunbar, R. I. M. (2002). Helping-at-the-nest and sex-biased parental investment in a Hungarian gypsy population. Current Anthropology, 43(5), 804-809.

Bowlby, E. J. M. (1969/1997). Attachment and loss: Attachment. Pimlico.

Colich, N. L., Platt, J. M., Keyes, K. M., Sumner, J. A., Allen, N. B., \& McLaughlin, K. A. (2019). Earlier age at menarche as a transdiagnostic mechanism linking childhood trauma with multiple forms of psychopathology in adolescent girls. Psychological Medicine, 50(7), 1090-1098.

Daly, M., \& Wilson, M. (1996). Evolutionary psychology and marital conflict: The relevance of stepchildren. In D. M. Buss, \& N. Malamuth, N. (Eds.), Sex, power, conflict: Feminist and evolutionary perspectives (pp. 9-28). Oxford University Press.

Danese, A., \& McEwen, B. S. (2012). Adverse childhood experiences, allostasis, allostatic load, and age-related disease. Physiology \& Behavior, 106(1), 29-39.

De Thierry, B. (2020). The simple guide to complex trauma and dissociation: What it is and how to help. Jessica Kingsley Publishers.

Dickemann, M. 1979. Female infanticide and the reproductive strategies of stratefield human societies. In N. A. Chagnon, \& W W. Irons (Eds.), Evolutionary biology and human social behaviour: An anthropological perspective (pp. 321-367). Duxbury Press.

Dube, S. R., Felitti, V. J., Dong, M., Giles, W. H., \& Anda, R. F. (2003). The impact of adverse childhood experiences on health problems: Evidence from four birth cohorts dating back to 1900. Preventive Medicine, 37(3), 268-277.

Ellis, B. J., \& Del Giudice, M. (2019). Developmental adaptation to stress: An evolutionary perspective. Annual Review of Psychology, 70(1), 111-139.

Friedman, S. H., Horwitz, S. M. \& Resnick, P. J. (2005). Child murder by mothers: A critical analysis of the current state of knowledge and a research agenda. American Journal of Psychiatry, 162, 1578-1587.

Griskevicius, V., Tybur, J. M., Delton, A. W., \& Robertson, T. E. (2011). The influence of mortality and socioeconomic status on risk and delayed rewards: A life history theory approach. Journal of Personality and Social Psychology, 100(6): 1015-1026.

Gunnar, M. R., DePasquale, C. E., Reid, B. M., Donzella, B., \& Miller, B. S. (2019). Pubertal stress recalibration reverses the effects of early life stress in postinstitutionalized children. Proceedings of the National Academy of Sciences, 116(48), 23984-23988.

Gurven, M., \& Kaplan, H. (2007). Longevity among hunter-gatherers: A cross-cultural examination. Population and Development Review, 33(2), 321-365.

Hanlon, G. (2016). Routine infanticide in the West 1500-1800. History Compass, 14(11), 535-548.

Heim, C. M., Entringer, S., \& Buss, C. (2019). Translating basic research knowledge on the biological embedding of early-life stress into novel approaches for the developmental programming of lifelong health. Psychoneuroendocrinology, 105, 123-137. 
Howell, N. (1979). Demography of the Dobe !Kung. Academic Press.

Hrdy, S. B. (1977). The langurs of Abu: Female and male strategies of reproduction. Harvard University Press.

Hrdy, S. B. (1999). Mother nature: Natural selection and the female of the species. Chatto \& Windus.

Hrdy, S. B. (2009). Mothers and others: The evolutionary origins of mutual understanding. Belknap Press of Harvard University.

Kampourakis, K. (2017). Making sense of genes. Cambridge University Press.

Lynch, K. E., Morandini, J. S., Dar-Nimrod, I., \& Griffiths, P. E. (2018). Causal reasoning about human behavior genetics: Synthesis and future directions. Behavior Genetics, 49, 221234.

Mathews, B. (2019). New international frontiers in child sexual abuse. Springer.

Milner, L. S. (2000). Hardness of heart / hardness of life: The stain of human infanticide. University Press of America.

Minde, K., Corter, C., Goldberg, S., \& Jeffers, D. (1990). Maternal preference between premature twins up to age four. Journal of the American Academy of Child \& Adolescent Psychiatry, 29(3), 367-374

Music, G. (2016). Nurturing natures: Attachment and children's emotional, social and brain development, $2^{\text {nd }}$ edn. Psychology Press.

Myers, S., \& Johns, S. E. (2017). Trade-offs in mother-infant bonding: A life history perspective on maternal emotional investments during infancy (Poster Presentation). 5th Annual Toulouse Economics and Biology Workshop: The evolution and economics of the family, Toulouse.

NICE (National Institute of Health and Clinical Excellence). (2017). Child abuse and neglect: NICE guideline. https://www.nice.org.uk/guidance/ng76/resources/child-abuse-andneglect-pdf-1837637587141

Reiss, M. J. (1990). Size, growth and reproduction: The logic of allometry. Evolutionary Theory, 9, 279-297.

Scheper-Hughes, N. (1992). Death without weeping: The violence of everyday life in Brazil. University of California Press. 
Schore, A. N., \& Sieff, D. F. (2015). On the same wavelength: How our emotional brain is shaped by human relationships. In Sieff, D. F. (Ed.), Understanding and healing emotional trauma: Conversations with pioneering clinicians and researchers (pp. 111136). Routledge.

Scott-Phillips, T. C., Dickins. T. E., \& West, S. A. (2011). Evolutionary theory and the ultimate-proximate distinction in the human behavioral sciences. Perspectives on Psychological Science, 6(1), 38-47.

Sieff, D. F. (1990). Explaining biased sex ratios in human populations: A critique of recent studies. Current Anthropology, 31(1), 25-48.

Sieff, D. F. (2019). The death mother as nature's shadow: Infanticide, abandonment, and the collective unconscious. Psychological Perspectives, 62(1), 15-34.

Singhi, P., Saini, A. G., \& Malhi, P. (2013). Child maltreatment in India. Paediatrics and International Child Health, 33(4), 292-300.

Stearns, S. (1992). The evolution of life histories. Oxford University Press.

St-Laurent, D., Dubois-Comtois, K., Milot, T., \& Cantinotti, M. (2019). Intergenerational continuity/discontinuity of child maltreatment among low-income mother-child dyads: The roles of childhood maltreatment characteristics, maternal psychological functioning, and family ecology. Developmental Psychopathology, 31(1), 189-202.

Sung, S., Simpson, J. A., Griskevicius, V., Kuo, S. I.-C., Schlomer, G. L., \& Belsky, J. (2016). Secure infant-mother attachment buffers the effect of early-life stress on age of menarche. Psychological Science, 27(5), 667-674.

Swanepoel, A., Sieff, D. F., Music, G., Launer, J., Reiss, M., \& Wren B. (2016) How evolution can help us understand child development and behaviour. BJPsych Advances, 22, 3643.

Swanepoel, A., Music, G., Launer, J., \& Reiss, M. (2017) How evolutionary thinking can help us understand ADHD. BJPsych Advances, 23, 410-418.

Tinbergen, N. (1963). On aims and methods of ethology. Zeitschrift für Tierpsychologie, 20, 410-433.

Turke, Paul W. 1988. Helpers at the nest: Childcare networks on Ifaluk. In Betzig, L., Borgerhoff Mulder, M. \& Turke, P. (Eds.), Human reproductive behavior: A Darwinian perspective (pp. 173-188). Cambridge University Press.

van IJzendoorn, M. H., Bakermans-Kranenburg, M. J., Coughlan, B., \& Reijman, S. (2020). Annual research review: Umbrella synthesis of meta-analyses on child maltreatment antecedents and interventions: differential susceptibility perspective on risk and resilience. Journal of Child Psychology and Psychiatry, 61(3), 272-290.

WHO. (2020). Factsheet: Child maltreatment. https://www.who.int/en/news-room/factsheets/detail/child-maltreatment

Wren, B., Launer, J., Reiss, M. J., Swanepoel, A., \& Music, G. (2019). Can evolutionary thinking shed light on gender diversity? BJPsych Advances, 25(6), 351-362. 